01

\title{
Применение КР-спектроскопии и методов квантовой химии для оценки относительного содержания триглицеридов олеиновой и линолиевой кислот в смеси оливкового масла и масла семян подсолнечника
}

\author{
(C) К.В. Березин ${ }^{1}$, К.Н. Дворецкий ${ }^{2}$, М.Л. Чернавина ${ }^{1}$, \\ А.В. Новоселова ${ }^{1}$, В.В. Нечаев ${ }^{3}$, Е.М. Антонова ${ }^{4}$, \\ И.Т. Шагаутдинова ${ }^{4}$, А.М. Лихтер ${ }^{4}$ \\ ${ }^{1}$ Саратовский национальный исследовательский государственный университет им. Н.Г. Чернышевского, \\ 410012 Саратов, Россия \\ ${ }^{2}$ Саратовский государственный медицинский университет им. В.И. Разумовского, \\ 410012 Саратов, Россия \\ ${ }^{3}$ Саратовский государственный технический университет им. Ю.А. Гагарина, \\ 410054 Саратов, Россия \\ ${ }^{4}$ Астраханский государственный университет, \\ 414056 Астрахань, Россия \\ ^e-mail: dcn@yandex.ru
}

Поступила в редакцию 09.04.2018 г.

\begin{abstract}
Зарегистрированы спектры КР пяти образцов масел семян подсолнечника и пяти образцов оливкового масла холодного отжима различных торговых марок в диапазоне $500-2000 \mathrm{~cm}^{-1}$. В рамках методов B3LYP/6$31 \mathrm{G}(\mathrm{d}) / 6-31 \mathrm{G}(\mathrm{d}, \mathrm{p}) / 6-31+\mathrm{G}(\mathrm{d}, \mathrm{p}) / 6-311 \mathrm{G}(\mathrm{d}) / 6-311 \mathrm{G}(\mathrm{d}, \mathrm{p}) / 6-311+\mathrm{G}(\mathrm{d}, \mathrm{p})$ построены структурные модели восьми жирных кислот: олеиновой, линолиевой, пальмитиновой, стеариновой, альфа-линоленовой, арахидоновой, эйкоза-пентаеновой и докозагексаеновой, а также в рамках метода B3LYP/6-31G(d) триглицеридов первых четырех из вышеописанных кислот. Рассчитаны колебательные волновые числа и интенсивности в спектрах ИК и КР. Используя супермолекулярный подход, проведено моделирование спектров КР оливкового масла и масла семян подсолнечника. Исследована зависимость относительной интенсивности колебательных полос $v_{\text {эксп }}=1660 \mathrm{~cm}^{-1}$ и $v_{\text {эксп }}=1445 \mathrm{~cm}^{-1}$ от содержания в маслах триглицеридов олеиновой и линолиевой кислот. Исследована зависимость интенсивности этих полос от степени насыщенности жирных кислот. Построены экспериментальная и эмпирические зависимости для оценки относительного содержания триглицеридов олеиновой и линолиевой кислот в смеси оливкового масла и масла семян подсолнечника. Обсуждена применимость методов теории функционала плотности совместно с колебательной спектроскопией для определения смесей растительных масел.
\end{abstract}

DOI: $10.21883 /$ OS.2018.09.46541.102-18

\section{Введение}

Известно, что спектроскопия КР является чувствительным, неразрушающим методом анализа различных жиров и липидов. Структурные особенности триглицеридов различных кислот заметно проявляются в колебательных спектрах, позволяя использовать спектроскопию КР как инструмент для качественного и количественного определения кислотного состава жиров.

Большой интерес к определению жирнокислотного состава масел растительного происхождения связан, с одной стороны, с важной ролью жиров в правильном рационе питания, с другой стороны, регистрация изменений в типичном жирнокислотном составе растительных масел позволяет отличить натуральный продукт от его фальсификата. Особенно это касается наиболее часто подделываемого оливкового масла, обладающего хорошими органолептическими свойствами и полезным воздействием на организм человека. Большое количество подделок связано с тем, что объемы мирового производства оливкового масла относительно небольшие, а цена его довольно высока по сравнению со многими другими растительными маслами. В связи с этим применению методов спектроскопии КР для исследования жирнокислотного состава различных масел растительного и животного происхождения посвящено довольно много работ [1-10]. В частности, в работах $[1,2]$ спектроскопия КР и последующий теоретический анализ методами частичных наименьших квадратов и главных компонент применялись для определения фальсификата оливкового масла при его разбавлении подсолнечным маслом и маслом фундука. В работе [3] показана возможность калибровки КР-спектрометра для определения процентного содержания в оливковом масле триглицерида линолиевой кислоты при выявлении его фальсификации путем разбавления растительными маслами. В работе [4] показано, что существует связь между интенсивностями экспериментальных КР-полос с волновыми числами 1265 и $1655 \mathrm{~cm}^{-1}$ и процентом 
содержания триглицеридов олеиновой и линолиевой кислоты в маслах, которая может быть использована при определении фальсификации оливкового масла.

В работе [5] использованы методы средней и ближней ИК спектроскопии, а также спектроскопии КР для дифференциации и определения подлинности пищевых масел и жиров, отмечается, что метод КР-спектроскопии по эффективности занимает промежуточное место между методами средней и ближней ИК спектроскопии. В работах [6,7] с помощью КР-спектроскопии определялось процентное содержание конъюгированной линолиевой кислоты в фотоизомеризованном соевом масле и коровьем молоке.

По данным хроматографического анализа различных масел [11] известно, что жирно-кислотную основу оливкового масла и масла семян подсолнечника составляют олеиновые (омега-9) и линоливые (омега-6) кислоты, из которых последняя является незаменимой, т.е. не синтезируется организмом из других кислот, а попадает в него только с пищей. При планировании правильного рациона питания очень важно соблюдать баланс как между незаменимыми полиненасыщенными кислотами омега-3 и омега-6, так и между полиненасыщенными и мононенасыщенными, из которых олеиновая кислота является самой распространенной. Таким образом, экспресс-анализ жирнокислотного состава наиболее употребляемых в пищевом рационе растительных масел необходим не только для выявления их фальсификации, но и для планирования правильного рациона питания.

В настоящей работе мы использовали спектроскопию КР совместно с супермолекулярным моделированием [12] спектральных свойств ряда оливковых масел и масел семян подсолнечника для оценки относительного содержания в их смеси триглицеридов олеиновой и линолиевой кислот.

\section{Методика эксперимента и расчета}

Экспериментальные исследования проводились на КР спектрометре QEPRO-RAMAN фирмы Ocean Optics (США) в диапазоне 500-2000 $\mathrm{cm}^{-1}$. Длина волны возбуждающего лазера $785 \mathrm{~nm}$. Разрешение прибора $8 \mathrm{~cm}^{-1}$. Для исследования были выбраны 5 образцов масел семян подсолнечника и 5 образцов оливкового масла, для которых экспериментально определен жирнокислотный состав [13]. Все образцы растительных масел были закуплены в продуктовых магазинах г. Саратова, РФ. Для построения экспериментальной зависимости и тестирования возможностей полученных в настоящей работе эмпирических зависимостей интенсивности КРполос от относительного содержания в смеси масел триглицеридов олеиновой и линолиевой жирных кислот дополнительно были зарегистрированы КР-спектры четырех объемных смесей $(20,40,60$ и 80\%) оливкового и масла семян подсолнечника соответственно.
Расчеты триглицеридов олеиновой, линолиевой, стеариновой и пальмитиновой кислот проводились методом B3LYP/6-31G(d), а расчеты отдельных жирных кислот методами B3LYP/6-31G(d)/6-31G(d,p)/6$31+\mathrm{G}(\mathrm{d}, \mathrm{p}) / 6-311 \mathrm{G}(\mathrm{d}, \mathrm{p}) / 6-311 \mathrm{G}(\mathrm{d}) / 6-311+\mathrm{G}(\mathrm{d}, \mathrm{p})$ по программе [14]. Дополнительно для исследования зависимости интенсивности некоторых КР-полос от степени насыщенности кислот были рассчитаны структуры и КР-спектры четырех жирных кислот, относящихся к классу омега-3: альфа линоленовой, арахидоновой, эйкозапентаеновой и докозагексаеновой.

Молекулярные модели оливкового масла и масла семян подсолнечника строились на основе четырех моделей жирных кислот (олеиновой, линолиевой, пальмитиновой и стеариновой). Содержание этих кислот в моделях устанавливалось таким, чтобы оно соответствовало усредненному значению для пяти исследуемых масел. Затем значения нормировались, чтобы их сумма была равна 100\%, так как содержание в маслах других типов жирных кислот не учитывалось. Таким образом, в модели оливкового масла содержание олеиновой кислоты составило $73.9 \%$, линолиевой $9.4 \%$, пальмитиновой $-13.5 \%$, стеариновой $-3.2 \%$, а для модели масла семян подсолнечника 64.1, 25.9, 6.6 и $3.4 \%$ соответственно. Теоретическое моделирование процесса фальсификации оливкового масла маслом семян подсолнечника проводилось путем изменения взаимного отношения олеиновой и линолиевой кислот с учетом общего изменения содержания насыщенных кислот при переходе от модели оливкового масла к модели масла семян подсолнечника. Теоретические КР-спектры моделей исследуемых масел строились по программе [15] в единицах сечения КР [16]. Полуширина всех лоренцевых контуров задавалась равной $10 \mathrm{~cm}^{-1}$. Для лучшего согласия с экспериментом вычисленные значения колебательных волновых чисел были скорректированы с помощью метода линейного масштабирования частот [17]. Интегральная интенсивность экспериментальных полос определялась путем подсчета количества пикселей в ограниченном снизу контуре при разрешении спектрограммы 600 dpi.

\section{Результаты и обсуждение}

Экспериментальные КР-спектры пяти образцов оливкового масла и масла семян подсолнечника показаны на рис. 1.

Как видно из рис. 1, в области $500-2000 \mathrm{~cm}^{-1}$ в КР-спектре рассматриваемых масел наблюдаются несколько интенсивных полос. Первые две из них $v_{\text {эксп }}=$ $=1660 \mathrm{~cm}^{-1}$ и $\nu_{\text {экп }}=1445 \mathrm{~cm}^{-1}$ согласно расчету образованы колебаниями только ненасыщенных частей жирно-кислотных цепей (синфазные валентные колебания связей $\mathrm{C}=\mathrm{C}$ ), а вторая только колебаниями насыщенных частей (деформационные ножничные колебания 

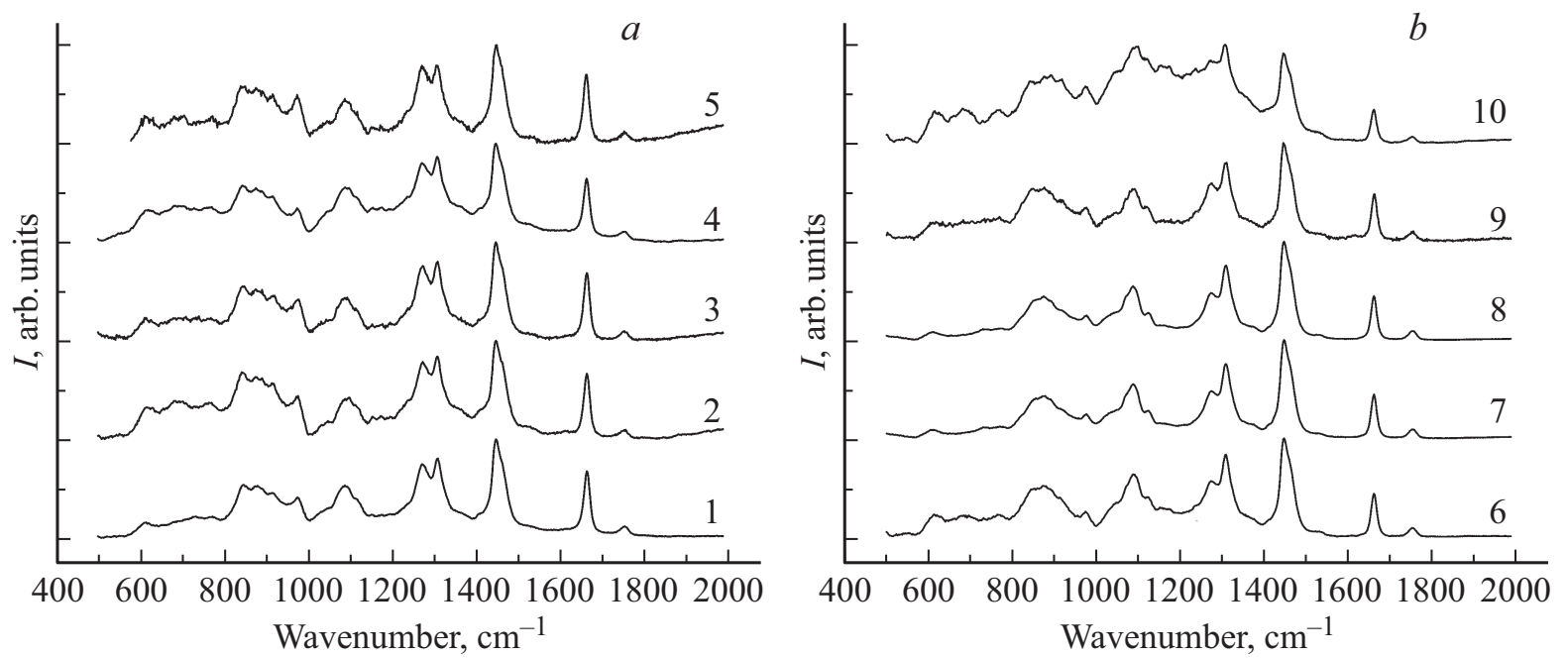

Рис. 1. Экспериментальные КР-спектры масел семян подсолнечника $(a)$ и оливковых масел $(b)$ в области $500-2000 \mathrm{~cm}^{-1}$. Цифрами на графиках обозначены номера образцов масел.

$\mathrm{CH}_{2}$-групп и концевой $\mathrm{CH}_{3}$-группы). Следующая частично разрешенная полоса имеет два максимума: первый $\nu_{\text {эксп }}=1306 \mathrm{~cm}^{-1}$ согласно расчету образован деформационными крутильными колебаниями $\mathrm{CH}_{2}$-групп, а второй $v_{\text {эксп }}=1270 \mathrm{~cm}^{-1}$ преимущественно деформационными синфазными колебаниями СН-связей ненасыщенных фрагментов. Таким образом, изменение длины жирнокислотных цепей или степени их ненасыщенности естественным образом отражается на интенсивности этих полос, что позволяет использовать их для оценки относительного содержания в растительных маслах ненасыщенных кислот. Для нашего исследования в качестве аналитических мы выбрали первые две полосы, поскольку они в КР-спектре не перекрываются и для определения интегральных интенсивностей не нужно проводить разделение контуров. Оставшиеся КР-полосы в этой частотной области образованы, согласно расчету, различными деформационными колебаниями СН-связей и $\mathrm{CH}_{2}$-групп, а также валентными колебаниями $\mathrm{C}-\mathrm{C}$-связей насыщенных участков цепей. Кроме этого, в спектре наблюдается слабая полоса $v_{\text {эксп }}=1750 \mathrm{~cm}^{-1}$, образованная валентными колебаниями $\mathrm{C}=\mathrm{O}$-связей карбонильных групп.

На рис. 2 представлено сравнение теоретических КРспектров олеиновой и пальмитиновой кислот, построенных с утроенными по величине значениями интенсивностей, и их триглицеридов, а также сравнение экспериментальных КР-спектров двух типов растительных масел со спектрами соответствующих теоретических моделей.

Как видно из рис. 2, $a$, глицериновая сшивка оказывает слабое влияние на КР-спектры жирных кислот в отличие, например, от ИК спектров [18]. Видно, что в данной спектральной области практически отсутствуют значимые частотные сдвиги, а интенсивность основных КР-полос фактически прямо пропорциональна числу цепей. Это позволяет при теоретическом моделировании
КР-спектров растительных масел использовать структурные модели только отдельных жирных кислот, что существенно экономит время теоретических расчетов. Чтобы установить, как волновые числа и относительная КР-интенсивность исследуемых полос зависит от выбора теоретического уровня, были сделаны расчеты рассматриваемых моделей жирных кислот с использованием шести стандартных базисных наборов. Результаты этих расчетов представлены в таблице.

Как видно из таблицы, относительная интенсивность рассматриваемых КР-полос, рассчитанная в рамках теоретического метода B3LYP, довольно сильно зависит от типа базисного набора. Расширение базисного набора, и особенно добавление в базис диффузных функций, приводит к существенному уменьшению значения относительной интенсивности для этих КР-полос. Сравнение этих значений со средними экспериментальными (4.11 для оливковых масел и 2.69 для масел семян подсолнечника) показывает, что лучшее согласие достигается при использовании базисного набора 6-31G(d). Довольно большое расхождение в значениях относительных интенсивностях КР-полос между теорией и экспериментом говорит о том, что использовать только теоретические данные, полученные в данной работе, для построения аналитической зависимости, которую можно было бы использовать в практических целях, не представляется возможным. Следует заметить, что несмотря на значительные расхождения в значениях относительных интенсивностей, их функциональная зависимость от содержания в маслах ОК и ЛК описывается в хорошем согласии с экспериментом. Функциональная зависимость носит нелинейный характер, так как КР-интенсивность рассматриваемых полос по-разному зависит от числа колебаний их формирующих.

На рис. 3 представлены теоретические зависимости интенсивности рассматриваемых КР-полос от числа де- 

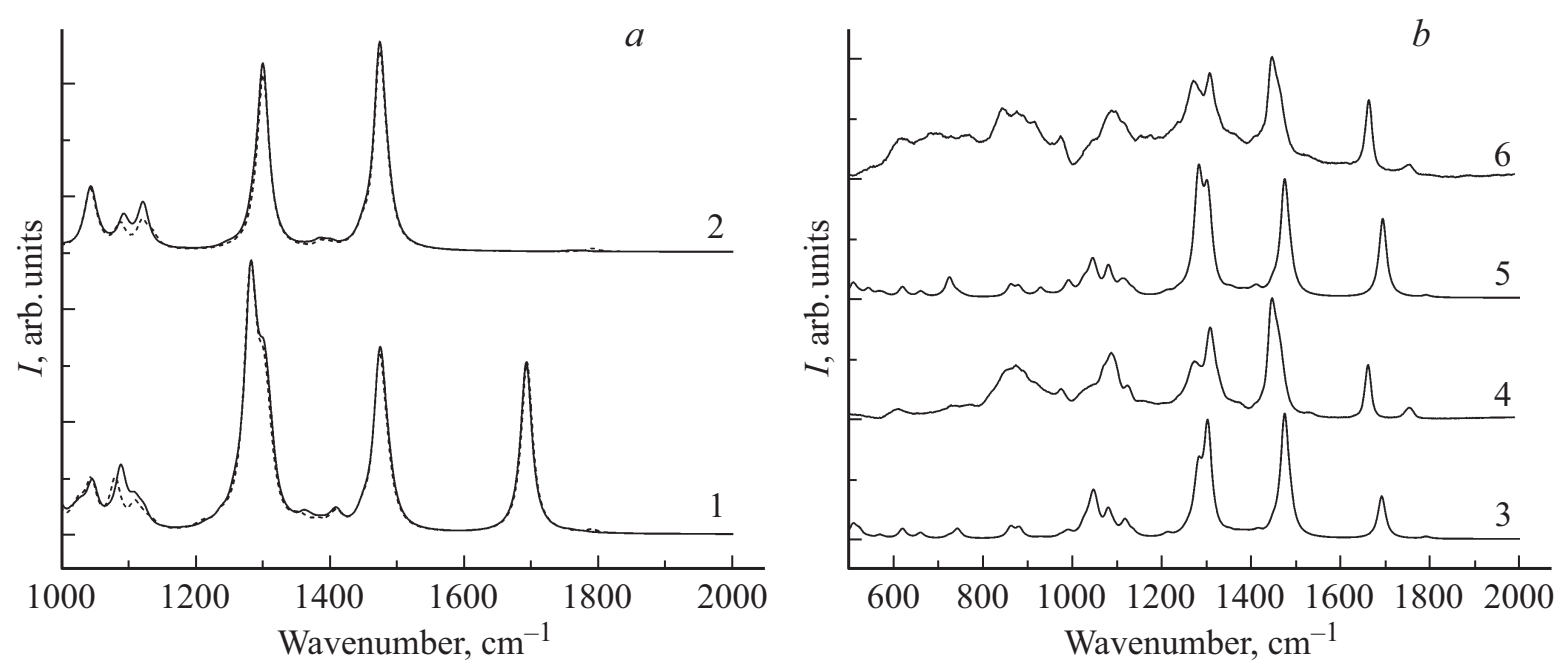

Рис. 2. Теоретические КР-спектры $(a)$ олеиновой кислоты 1 , пальмитиновой кислоты 2 , построенные с утроенными по величине значениями интенсивностей (пунктирная линия) и их триглицеридов (сплошная линия), а также экспериментальные спектры образцов оливкового 4 и масла семян подсолнечника 6, и спектры теоретических моделей этих масел $3,5(b)$, рассчитанные методом B3LYP/6-31G(d).

Волновые числа $\left(\mathrm{cm}^{-1}\right)$ и относительные интенсивности (значения в скобках) двух КР-полос в спектрах ненасыщенных жирных кислот и моделей оливкового масла и масла семян подсолнечника, рассчитанные в рамках метода B3LYP с различными базисными наборами

\begin{tabular}{c|c|c|c|c|c|c}
\hline \multirow{2}{*}{$\begin{array}{c}\text { Жирные кислоты } \\
\text { и модели масел }\end{array}$} & \multicolumn{6}{|c}{ Базисные наборы } \\
\cline { 2 - 7 } & $6-31 \mathrm{G}(\mathrm{d})$ & $6-31 \mathrm{G}(\mathrm{d}, \mathrm{p})$ & $6-31+\mathrm{G}(\mathrm{d}, \mathrm{p})$ & $6-311 \mathrm{G}(\mathrm{d})$ & $6-311 \mathrm{G}(\mathrm{d}, \mathrm{p})$ & $6-311+\mathrm{G}(\mathrm{d}, \mathrm{p})$ \\
\hline Олеиновая кислота & $1517 / 1743(3.38)$ & $1502 / 1740(3.26)$ & $1493 / 1722(1.71)$ & $1502 / 1726(2.48)$ & $1491 / 1721(2.32)$ & $1489 / 1714(1.59)$ \\
\hline Линолевая кислота & $1517 / 1746(1.28)$ & $1502 / 1744(1.24)$ & $1493 / 1725(0.68)$ & $1502 / 1730(0.94)$ & $1491 / 1725(0.89)$ & $1489 / 1717(0.64)$ \\
\hline $\begin{array}{c}\text { Модель } \\
\text { оливкового масла }\end{array}$ & $1517 / 1744(3.47)$ & $1502 / 1741(3.35)$ & $1493 / 1722(1.78)$ & $1502 / 1727(2.39)$ & $1491 / 1722(1.65)$ & $1489 / 1714(2.56)$ \\
\hline $\begin{array}{c}\text { Модель масла } \\
\text { семян подсолнечника }\end{array}$ & $1517 / 1746(1.77)$ & $1502 / 1744(1.71)$ & $1493 / 1725(0.94)$ & $1502 / 1730(1.24)$ & $1491 / 1725(0.88)$ & $1489 / 1717(1.31)$
\end{tabular}

формационных колебаний $\mathrm{CH}_{2-}, \mathrm{CH}_{3}$-групп и валентных колебаний связей $\mathrm{C}=\mathrm{C}$, их образующих.

Из рис. 3 видно, что с увеличением степени ненасыщенности жирнокислотной цепи интенсивность КРполосы, образованной валентными $\mathrm{C}=\mathrm{C}$-колебаниями, довольно быстро линейно возрастает. При равенстве длин жирнокислотных цепей с ростом степени насыщенности количество $\mathrm{CH}_{2}$-групп пропорционально уменьшается, что приводит к снижению интенсивности второй КР-полосы, но спад интенсивности происходит значительно медленнее, чем ее рост в первом случае.

При теоретическом моделировании зависимости относительной интенсивности КР-полос от содержания в смеси двух типов рассматриваемых масел олеиновой и линолиевой кислот дополнительно учитывался тот факт, что среднее содержание насыщенных кислот в них различны. Так, например, в оливковом масле это значение равно $16.3 \%$, а в масле семян подсолнечника 9.8\%. Этот учет позволяет улучшить согласие с экспериментом, так как в интенсивность КР-полосы $v_{\text {эксп }}=1445 \mathrm{~cm}^{-1}$ вносят вклад деформационные колебания как ненасыщенных, так и насыщенных кислот. На рис. 4, $a$ представлена зависимость, учитывающая это изменение. Она носит логарифмический характер и описывается следующим выражением: $y=0.09 \ln (x)+0.83$, где $x$ - отношением концентраций олеиновой и линолиевой кислот, $y-$ разница между экспериментальными и теоретическими значениями относительной интенсивности КР-полос смесей рассматриваемых масел.

На рис. 4, $b$ представлены теоретические зависимости относительной интенсивности двух КР-полос от соотношений концентраций олеиновой и линолиевой кислот, построенные с разной параметризацией. В первом случае зависимость построена только по данным теоретических расчетов методом B3LYP/6-31G(d). Во 

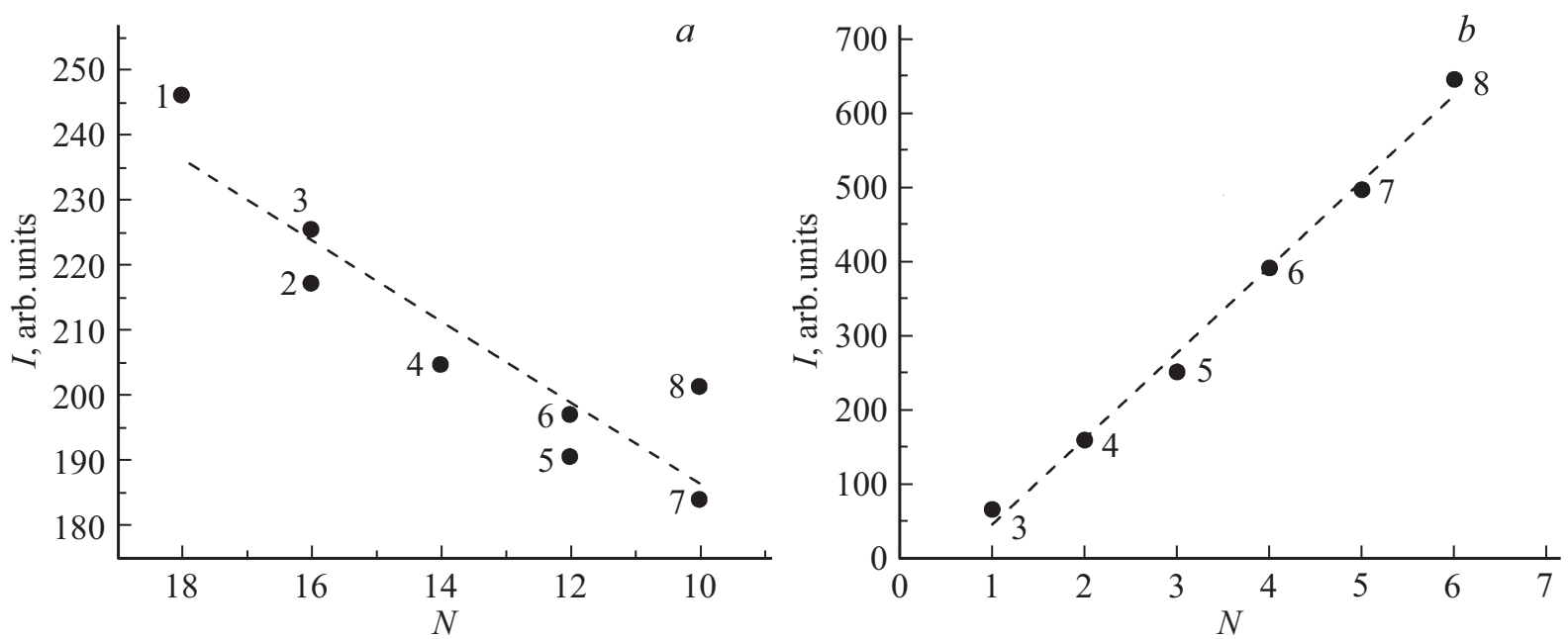

Рис. 3. Теоретическая зависимость интенсивности КР-полос $v_{\text {эксп }}=1445 \mathrm{~cm}^{-1}$ от числа деформационных колебаний $\mathrm{CH}_{2}$-, $\mathrm{CH}_{3}$ групп $(a)$ и $v_{\text {экп }}=1660 \mathrm{~cm}^{-1}$ от числа валентных колебаний связей $\mathrm{C}=\mathrm{C}(b)$ в спектрах жирных кислот: пальмитиновая $(1)$; стеариновая (2); олеиновая (3); линолевая (4); $\alpha$-линоленовая (5); архидонтовая (6); эйкозапентаеновая (7) и докозагексаеновая $(8)$, рассчитанная методом B3LYP/6-31G(d).
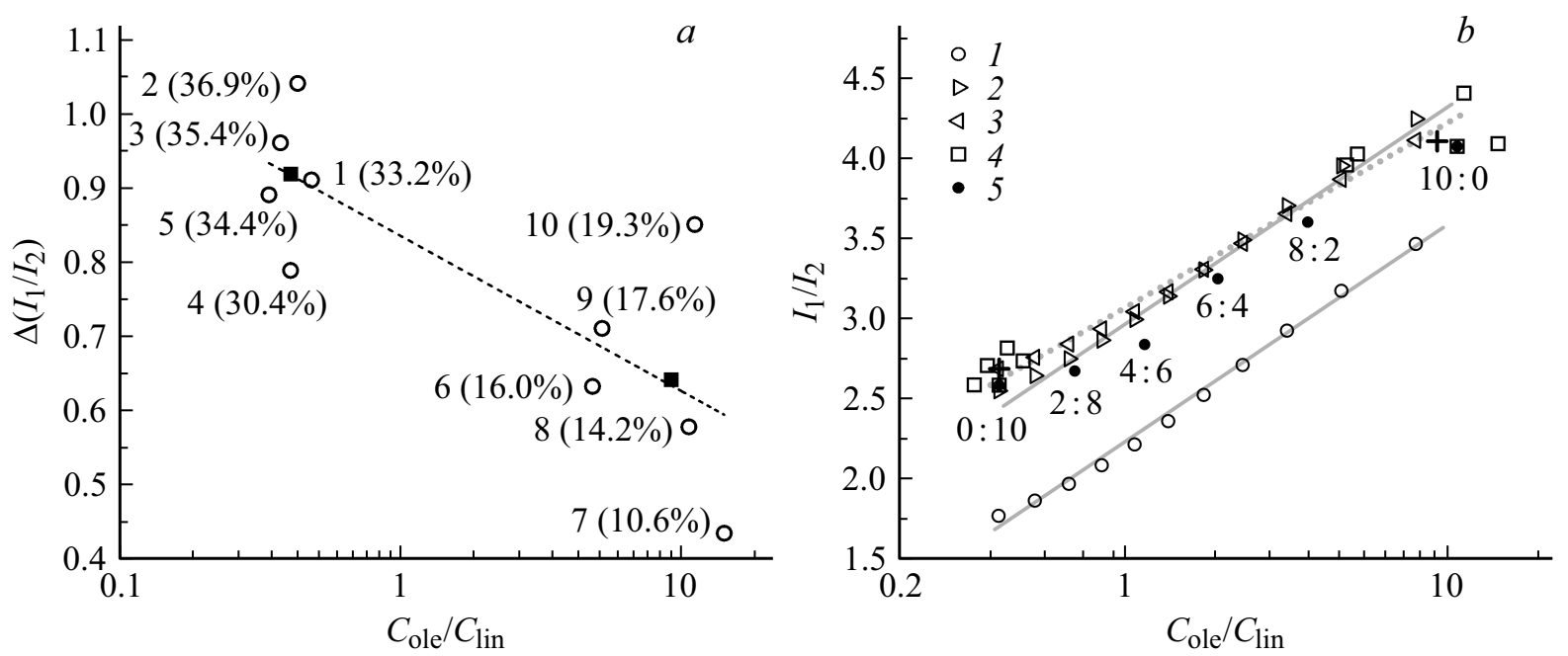

Рис. 4. Разница $(a)$ между экспериментальными значениями относительной интенсивности КР-полос и полученными в ходе моделирования КР-спектров 10 образцов растительных масел (цифрами на графике обозначены номера образцов: 1-5 масла семян подсолнечника, 6-10 оливковые масла; в скобках - разница между экспериментальными и теоретическими значениями в процентах). Квадратами на графике отображены средние значения для образцов масла семян подсолнечника и оливкового масла; пунктирной линией - аппроксимация зависимости разницы между экспериментальными и теоретическими значениями и отношением олеиновой и линолиевой кислот в образцах. Зависимости $(b)$ относительной интенсивности КР-полос от соотношений концентраций олеиновой и линолиевой кислот, построенные с разной параметризацией: 1 - модель, построена на основе только теоретических расчетов; 2 - модель, построенная на основе теоретических расчетов с учетом эмпирического коэффициента сдвига 0.78; 3 - модель, построенная на основе теоретических расчетов с учетом функциональной зависимости, представленной на рис. 4, a. Квадратами 4 показаны экспериментальные значения относительных интенсивностей КР-полос для образцов оливкового масла (группа точек справа) и масел семян подсолнечника (слева); плюсами обозначены их средние значения. Точками 5 обозначены экспериментальные результаты для смеси одного из образцов оливкового масла и масла семян подсолнечника (цифрами внизу дано соотношение концентраций этих масел в смеси).

втором случае в качестве эмпирического параметра использовался коэффициент сдвига $(0.78)$, который рассчитывался как среднее значение разницы между экспериментальными значениями относительной интенсивности КР-полос и полученными в ходе моделирования
КР-спектров 10 образцов растительных масел, представленных на рис. 4, $а$. Эта зависимость описывается уравнением $y=0.59 \ln (x)+3.01(x, y$ описаны выше) и наиболее хорошо подойдет для определения процентного содержания олеиновой и линолиевой кислот 
в смеси оливкового маслах и маслах семян подсолнечника, близкой к отношению $1: 1$. В третьем случае в качестве корректирующего параметра была выбрана функциональная зависимость разницы между экспериментальными и теоретическими значениями относительной интенсивности КР полос от соотношений концентраций олеиновой и линолиевой кислот в исследуемых образцах растительных масел, также представленной на рис. 4, $a$. Эта зависимость описывается уравнением $y=0.50 \ln (x)+3.06$. Она является универсальной и может быть использована при оценке как процентного содержания олеиновой и линолиевой кислот в чистых маслах, так и в их смесях и соответственно для определения фальсификации оливкового масла холодного отжима маслом семян подсолнечника. При использовании этой зависимости средняя ошибка в определении доли оливкового масла в смеси двух масел составила 5\%. Кроме этого, была определена зависимость, основанная только на экспериментальных данных, которая описывается уравнением $y=0.49 \ln (x)+2.91$ и может также использоваться для определения фальсификации оливкового масла.

\section{Заключение}

Зарегистрированы экспериментальные КР-спектры пяти образцов оливкового масла холодного отжима и пяти образцов масел семян подсолнечника в диапазоне $500-2000 \mathrm{~cm}^{-1}$. В рамках теоретического метода B3LYP с шестью стандартными базисными наборами гауссовских функций 6-31G(d), 6-31G(d,p), 6-31+G(d,p), 6-311G(d), 6-311G(d,p), 6-311+G(d,p) построены структурные модели и рассчитаны спектральные характеристики восьми жирных кислот: олеиновой, линолиевой, пальмитиновой, стеариновой, альфа-линоленовой, арахидоновой, эйкозапентаеновой и докозагексаеновой, а также в рамках метода B3LYP/6-31G(d) триглицеридов первых четырех кислот.

Используя супермолекулярный подход, проведено моделирование колебательного КР спектра оливкового масла холодного отжима и масла семян подсолнечника. Установлена функциональная связь между относительной интенсивностью двух экспериментально наблюдаемых КР полос $v_{\text {эксп }}=1660 \mathrm{~cm}^{-1}$ и $v_{\text {эксп }}=1445 \mathrm{~cm}^{-1}$ от содержания в маслах триглицеридов олеиновой и линолиевой кислот, которая хорошо аппроксимируется логарифмической зависимостью.

Показано, что использованные в работе теоретические методы без эмпирической коррекции не обеспечивают хорошего согласия с экспериментом при описании такой функциональной зависимости.

Проведено экспериментальное и теоретическое моделирование процесса разбавления оливкового масла холодного отжима маслом семян подсолнечника, в результате которого получены функциональные зависимости, которые могут быть использованы на практике как для оценки относительного содержания олеиновых и линолиевых кислот в оливковых маслах и маслах семян подсолнечника, так и для оценки доли масла семян подсолнечника в смеси при фальсификации оливкового масла холодного отжима.

Работа выполнена при финансовой поддержке в рамках государственных заданий высшим учебным заведениям и научным организациям в сфере научной деятельности, полученных от Минобрнауки. Рег. номер: 3.9128.2017/БЧ.

\section{Список литературы}

[1] Lopez-Diez E.C., Bianchi G., Goodacre R. // J. Agric. Food Chem. 2003. V. 51. N 21. P. 6145. doi $10.1021 / \mathrm{jf034493d}$

[2] El-Abassy R.M., Donfack P., Materny A. // J. Raman Spectrosc. 2009. V. 40. N 9. P. 1284. doi 10.1002/jrs.2279

[3] Baeten V., Aparicio R. // Biotechnol. Agron. Soc. Environ. 2000. V. 4. N 4. P. 196.

[4] Zhang X., Zou M., Qi X., Liu F., Zhang C., Yin F. // J. Raman Spectrosc. 2011. V. 42. N 9. P. 1784. doi 10.1002/jrs.2933

[5] Yang H., Irudayaraj J., Paradkar M.M. // Food Chemistry. 2005. V. 93. N 1. P. 25. doi 10.1016/j.foodchem.2004.08.039

[6] Bernuy B., Meurens M., Mignolet E., Turu C., Larondelle Y. // J. Agric. Food Chem. 2009. V. 57. N 15. P. 6524. doi 10.1021/j9003237

[7] Meurens M., Baeten V., Yan S.H., Mignolet E., Larondelle Y. // J. Agric. Food Chem. 2005 V. 53. N 15. P. 5831. doi 10.1021/jf0480795

[8] Abbas O., Fernandez Pierna J.A., Codony R., von Holst C., Baeten V. // J. Mol. Struct. 2009. V. 924-926. P. 294. doi 10.1016/j.molstruc.2009.01.027

[9] Motoyama M., Ando M., Sasaki K., Nakajima I., Chikuni K., Aikawa K., Hamaguchi H.O. // Food Chem. 2016. V. 196. P. 411. doi 10.1016/j.foodchem.2015.09.043

[10] El-Abassy R.M., Eravuchira P.J., Donfack P., von der Kammer B., Materny A. // Vib. Spec-trosc. 2011. V. 56. N 1. P. 3. doi 10.1016/j.vibspec.2010.07.001

[11] Кодекс Алиментариус. Жиры, масла и производные продукты. М.: Весь Мир, 2007. 68 с.; Codex Alimentarius. Fats, oils and related products. Rome: Food and Agriculture Organization, 2001. $81 \mathrm{p}$.

[12] Березин К.В., Шагаутдинова И.Т., Чернавина М.Л., Новоселова А.В., Дворецкий К.Н., Лихтер А.М. // Опт. и спектр. 2017. T. 123. № 3. C. 472; Berezin K.V., Chernavina M.L., Novoselova A.V., Shagautdinova I.T., Likhter A.M., Dvoretskii K.N. // Opt. Spectrosc. 2017. V. 123. N 3. P. 495. doi 10.1134/S0030400X17090089

[13] [Электронный ресурс] Режим доступа: https://roscontrol.com/category/produkti/ rastitelnoe_maslo/

[14] Frisch M.J., Trucks G.W., Schlegel H.B. et al. Gaussian03, Revision B.03. Gaussian03 Inc., Pittsburgh PA. 2003.

[15] Файфель А.Б., Березин К.В., Нечаев В.В. Программа для моделирования и визуализации колебательных ИК и КР-спектров по данным квантово-механических расчетов. Проблемы оптической физики. Саратов: Изд-во ГосУНЦ „Колледж“, 2003. С. 74. 
[16] Березин К.В., Кривохижина Т.В., Нечаев В.В. // Опт. и спектр. 2004. Т. 97. № 4. С. 567; Berezin K.V., Krivokhizhina T.V., Nechaev V.V. // Opt. Spectrosc. 2004. V. 97. N 4. P. 530. doi 10.1134/1.1813693

[17] Березин К.В., Нечаев В.В., Кривохижина Т.В. // Опт. и спектр. 2003. T. 94. № 3. C. 398; Berezin K.V., Nechaev V.V., Krivokhizhina T.V. // Opt. Spectrosc. 2003. V. 94. N 3. P. 357. doi 10.1134/1.1563679

[18] Березин К.В., Лихтер А.М., Шагаутдинова И.Т., Чернавина М.Л., Нечаев В.В. Экспериментальный FT-IR спектр масла косточки винограда и молекулярные модели триглицеридов жирных кислот // Проблемы оптической физики и биофотоники. Саратов : Изд-во Новый ветер. 2016. C. 95 . 